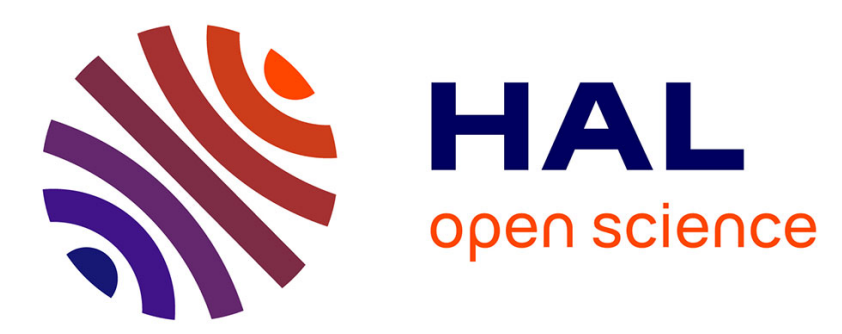

\title{
A historical perspective on learning: the legacy and actuality of I. M. Pavlov and N. A. Bernstein
}

Agnès Roby-Brami, Rémi Goasdoué

\section{To cite this version:}

Agnès Roby-Brami, Rémi Goasdoué. A historical perspective on learning: the legacy and actuality of I. M. Pavlov and N. A. Bernstein. Rethinking physical and rehabilitation medicine, Springer, pp.71-93, 2010, 978-2-8178-0033-2. 10.1007/978-2-8178-0034-9_4 . halshs-01383006

\section{HAL Id: halshs-01383006 https://shs.hal.science/halshs-01383006}

Submitted on 18 Oct 2016

HAL is a multi-disciplinary open access archive for the deposit and dissemination of scientific research documents, whether they are published or not. The documents may come from teaching and research institutions in France or abroad, or from public or private research centers.
L'archive ouverte pluridisciplinaire HAL, est destinée au dépôt et à la diffusion de documents scientifiques de niveau recherche, publiés ou non, émanant des établissements d'enseignement et de recherche français ou étrangers, des laboratoires publics ou privés. 


\section{A historical perspective on learning: the legacy and actuality of I. M. Pavlov and N. A. Bernstein}

Chapter · January 2010

DOI: $10.1007 / 978-2-8178-0034-9 \_4$

CITATIONS

0

4 authors, including:

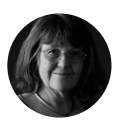

\section{Agnes Roby-Brami}

Pierre and Marie Curie University - Paris 6 157 PUBLICATIONS 3,524 CITATIONS SEE PROFILE
Jean-Pierre Didier

University of Burgundy

124 PUBLICATIONS 770 CITATIONS

SEE PROFILE

Some of the authors of this publication are also working on these related projects:

Project motor adaptation in rehabilitation process View project 


\section{An historical perspective on learning: The legacy and actuality of IM Pavlov and NA Bernstein.}

Agnès Roby-Brami ${ }^{1,2}$ and Rémi Goasdoué . $^{3}$

1- Labororatoire Neurophysique et Physiologie, Université Paris Descartes, UMR 8119 45 rue des Saints Pères, 75006 Paris.

2- Service de Médecine Physique, Hôpital Raymond Poincaré, 92380 Garches.

3- Education et apprentissages, EA 4071, Université Paris Descartes, UMR 8119 45 rue des Saints Pères, 75006 Paris

In: Rethinking physical and rehabilitation medicine.

Ed J.P. Didier, E. Bigand, Université de Bourgogne. (2010)

Springer. Series on the European academy of rehabilitation medicine. pp 71-94. 


\section{Introduction}

The aim of the present chapter is to examine the mechanism of learning at the level of sensorimotor functions rather than at a higher cognitive level. Indeed, although the mechanisms sub-serving motor control and learning are still disputed, it is generally admitted that the control of even the simplest gesture such as pointing or grasping implies initial learning during development as a child and continuous adaptation to the context of action.

Learning is defined as a relatively permanent modification of the organism's activity resulting from its interactions with the external environment. There are two theoretical streams: the main stream that we may call very schematically computo-representational neurosciences, which aims to improve understanding of the physiology of the nervous system, and various alternative approaches that share a more systemic or dynamical point of view, with strong references to psychology and a common aim to understand human activity. These two approaches differ on some important points, particularly on the question of the mechanisms of learning. This debate would necessitate an extensive and detailed review of the experimental, theoretical and modeling evidences supporting or refuting both approaches, which are well beyond the scope of this chapter. We chose to tackle the question from an historical point of view, through the controversy that occurred between Pavlov and Bernstein during the 30's.

Pavlov, Nobel Prize winner, is universally recognized as the discoverer of classical conditioning (46). Bernstein was a younger contemporary of Pavlov, now recognized as an important pioneer in the field of motor control. In 1936, he wrote a book "Contemporary issues on the physiology of the central nervous system" expressing his disagreement with Pavlov's views on motor learning, which remained unpublished until 2003 (8). Beyond the hard historical context, this controversy gives us the opportunity to review the scientific and epistemic lineage of these two great scientists. In our opinion, their controversy personalizes the still current confrontation between two key concepts: "reflexes" and "activity", to apprehend the multiple aspects and levels of learning nowadays. The ideas of Pavlov and the concept of reflexes have structured the development of research both in psychology and neuroscience right up until to today. In contrast, the ideas of Bernstein were forgotten until their recent reappraisal in the 70's and remain less recognized outside the specific field of motor control. The aim of this chapter is to suggest that the ideas he developed should be better considered and analyzed, in particular their potential applications for education and rehabilitation.

\section{Biographies and historical context of the controversy between Pavlov and Bernstein}

Biography of Ivan Petrovich Pavlov

Pavlov was a Russian physiologist, psychologist, and physician who is universally known for his work on conditioned reflexes. He is considered as a pioneer in many fields such as psychology, integrated physiology and neuroscience.

Pavlov was born on September 14, 1849 at Ryazan, where his father was a village priest. He was educated at the theological seminary at Ryazan. Pavlov decided to devote his life to natural science. During his brilliant academic career, he directed the Department of Physiology at the Institute of Experimental Medicine from 1890 to the end of his life (45 years). This centre became one of the most important for physiological research.

Pavlov was mainly inspired by the progressive ideas of I. M. Sechenov, the father of Russian physiology, who investigated the physiological basis of mental processes and postulated that the mnesic trace of past sensations could be recalled by the evocation of any of its parts (nowadays called cued recall). In the 1890s, Pavlov investigated the neural control of digestion in dogs by externalizing a salivary gland so he could collect, measure, and analyze the saliva and its responses to food under different conditions. He noticed that the dogs tended to salivate before food was actually delivered to their mouths, and set out to investigate this "psychic secretion", as he called it after Sechenov. He then carried out a long series of experiments in which he manipulated the stimuli occurring before the presentation of food. He determined several basic laws for the 
establishment and extinction of what he called "conditioned reflexes" that are the basis of the theory he developed until the end of his life (45, review in 57).

Pavlov's experiments on digestion earned him the 1904 Nobel Prize in Physiology and Medicine (47). In 1907, he was elected Academician of the Russian Academy of Sciences; and received in the following years many honorary memberships abroad.

After the October Revolution, a special government decree, signed by Lenin on January 24, 1921, noted «the outstanding scientific services of Academician I.P. Pavlov, which are of enormous significance to the working class of the whole world». Pavlov and his collaborators were given unlimited scope for scientific research, and received continuous government support despite Pavlov's critical opinions of the soviet regime (50).

The 15th International Physiological Congress, consecrating his work was held in Leningrad and Moscow in 1935. Pavlov nurtured a great school of physiologists, which produced many pupils who continued to develop his ideas along with a host of followers all over the world. IM Pavlov died in Leningrad on February 27, 1936.

Conditioned reflexes and Pavlov's theory.

Pavlov described conditioned reflexes in detail and used his observations to theorize upon the functioning of the brain and mental activity (46). Conditioned reflexes are based on the stimulusresponse paradigm. Any external agent (the conditional stimulus) can, by coinciding in time with an ordinary reflexe (e.g. food which is the unconditional stimulus of salivation), become the signal for the formation of a new artificial conditioned reflex. Thus, conditioning creates a new link between the conditional stimulus and the response. Pavlov emphasized the importance of repetition for the formation of this new link. He paid particular attention to the experimental conditions especially timing and selectivity of the stimuli. To this purpose, he built a laboratory some years later in St. Petersburg with a complicated system of acoustic insulation necessary for the experiments; the so called "Tower of Silence" (57).

Pavlov's objective was to study all psychic activity objectively, instead of resorting to subjective methods and to experimentally investigate the most complex interrelations between an organism and its external environment. "A conditioned reflex should be regarded as an elementary psychological phenomenon, which at the same time is a physiological one. It followed from this that the conditioned reflex was a clue to the mechanism of the most highly developed forms of reaction in animals and humans to their environment and it made an objective study of their psychic activity possible" (45). Thus Pavlov rejected the subjective interpretation of «psychic» salivary secretion. More generally, for him all psychic activity was of a reflex nature - though not a permanent but a temporary or conditioned reflex. He was also interested in language that he called the second system of signalization (the external or internal stimulations being the first system of signalization) and this field was further developed by his followers. His objectivism was very innovative at that time by reference to contemporary psychophysics. The work of Pavlov largely developed and popularized the stimulus-response paradigm which dominated experimental psychology until the 60's.

The method of conditioned reflexes allowed Pavlov to analyze the mechanism of "higher nervous function" in the cerebral cortex (46). He considered learning as a formation of connections among cortical centers parallel to the formation of associations at the psychological level. Although he was inspired by his contemporary, C.S. Sherrington (1857-1952) who investigated the neuronal bases of spinal reflexes, Pavlov did not directly investigate the neuronal bases of behavior ${ }^{1}$. His findings on brain physiology were based on the demonstration of active inhibitory processes and the analysis of complex interplay between excitation and inhibition during conditioning and not through lesional experiments which he used very little himself. "... conditioning is accompanied by excitatory and inhibitory processes extending over the hemispheres according to a variety of laws" (16).

1 In contrast, Pavlov's ambition to understand psychological phenomenon by using objective physiological method departs from the Sherrington's views (13). 
Classical conditioning is recognized as a precursor of learning theory. However, Pavlov distinguished two mechanisms of association leading to modification of activity: adaptation though conditioning and learning through "trial and error" (developed later by Skinner in behaviorism). Pavlov thought that conditioned reflexes were at the basis of rapid adaptation to the environment and reserved the term of learning to the acquisition of knowledge resulting from trial and error. He though that, unlike associations due to conditioned reflexes which could easily be extinguished, associations learned by trial and error were more stable and long lasting (69).

In the late part of his life, Pavlov worked on conditioning animals to pain and described the organism's response to overwhelming stimuli, what he called transmarginal inhibition.

\section{Biography of Nicolaï Alexandrovitch Bernstein}

Although much less universally known than Pavlov, Bernstein is recognized by the scientific community, even by his detractors, as a pioneer in the knowledge of action and movement control both in psychology and neurosciences and as a founder of cybernetics.

N.A. Bernstein was born in Moscow in 1896, his father was a well known psychiatrist and his uncle a famous mathematician. After finishing his medical studies, he served as medical doctor in the Red Army (1919-1921) then worked as a neuropsychologist. In 1922 he was recruited by the laboratory of Biomechanics in the central institute of work in Moscow. In 1930-1941 he headed the laboratory of biomechanics in the central scientific institute of physical activity and set up biomechanics laboratories in other institutions. His method (Kymocyclography) directly stems from Marey's Chronophotography (Marey 1830-1904) with some technical improvement such as 3D recordings and mathematical signal processing. Bernstein was particularly interested in the details of human movements and their variability with the double purpose of improving working conditions and understanding the underlying neuropsychological mechanisms.

Bernstein's observation of movement variability brought him to propose his theory on hierarchical control of action and movement coordination. He was influenced by the theory of dynamical systems investigated by the mathematicians Lyapunov (1857-1918) and Andronov (1901-1952) and he adapted these ideas on the organization of autonomous systems to the physiology of the motor system. He was also particularly interested and influenced by the neurophysiological works of Charles S Sherrington (1857-1952) and Alfred Fessard (1900-1982). He deepened his theoretical thinking along with the ideas of the psychologist L. Vygotski (18961934) on the role of the material and social environment for development (see 56). He proposed a general theory of activity of the living organism that he named "physiology of activity" as a tribute to Vygotski who proposed "psychology of activity".

Bernstein focused on action and the achievement of goals and not to a chaining of reflexes. This brought him to criticize Pavlov's theory in a book "Contemporary studies on the physiology of nervous system" written during the 30's (7). This text is not so much a critique of the works of Pavlov himself but of the application of his theory to mental action and language by his pupil A.G. Ivanov-Smolenski. Mainly, it was an opportunity for Bernstein to present his own vision of cerebral function and particularly to transpose the paradigm of activity to physiology. The book was ready for publication, and proofs signed, when Pavlov died in 1936. Bernstein then refused the publication since he considered he should not argue against an opponent who could not answer ${ }^{2}$.

Bernstein spent the period of the war in Tashkent. Back in Moscow, he received recognition for the practical applications of his works (in sport, for bracing in rehabilitation, and for the training of cosmonauts). In 1947 he received the Stalin prize for his major book "The construction of movement" (8) which has never been integrally translated in English. In 1949, Bernstein was accused, during the anti-semite campaign of "violating the principles of the party and the historical perspective". In 1950 a session of the Academy of Science proclaimed that Pavlov's doctrine was the official doctrine of the communist party. Considered as a public enemy, Bernstein was fired and

\footnotetext{
${ }^{2}$ His student Pr Iosif Moiseevitch Feigenberg, kept the proofs until now and directed the publication in 2003 in Moscow. This book is unfortunately still not translated despite its importance for the History of Science.
} 
his laboratory closed. Never disowning his convictions, shut in his home, he devoted his next years to writing. In particular, he wrote a pedagogical book "On dexterity and his development" which remained unpublished until 1991 (9).

Bernstein was rehabilitated after Stalin's death in 1953 and worked in the institute of neurology until his death in 1956 where he participated in a multidisciplinary seminar devoted to cybernetics (see below). Since Bernstein's death, in 1966 the institute of higher nervous activity continues his work on motor coordination, keeps his archives and promotes his thinking.

\section{The psychology of activity}

The concept of activity was developed by Soviet psychologists in the 30's (in particular the "Troïka": Vygotski (1896-1934), Leontiev (1903-1979) and Luria (1902-1977), (see 56) and transposed into physiology by Bernstein. This concept is at the heart of the controversy between Bernstein and Pavlov.

The concept of activity is a genuine paradigm shift mainly proposed as an alternative for the classic "stimulus - response" scheme. Leontiev suggested that the development of research in psychology needs to get beyond this debate which began in XIXth psychophysics (39). This dualism leads the subject to be considered as passively receiving stimulations from his environment. Yet, the work by soviet psychologists and Bernstein showed that perception is active since it implies exploration. In addition, studying only responses conceals the processes which determine the response. Vygotski qualified the responses as «fossilized behavior» since they are only traces of activity. The definition by Leontiev "Activity is the non additive, molar unit of life for the material corporeal subject $\gg$ clearly shows the paradigm shift: the unit for analysis is no longer response but activity as a whole.

In the following section, we present the general properties of "psychology of activity" (reviewed in 39) and show how they were continued and adapted by Bernstein for his "physiology of activity".

Goal-directed activity and levels of description

The active dimension of activity is given the principal place and much of this work focuses on the motives of activity. Every activity is goal directed, and the motive needs to be considered in order to understand its organization. The following example illustrates this principle and the structure of activity in three levels: to feed his family (motive) a person can go hunting (action), but the tools and techniques will not be the same depending on the hunted quarry (operations) (39). Bernstein follows the principle of a hierarchical description but more precisely focused at the level of operations. The highest level for Bernstein corresponds to Leontiev's "actions" and describes the goal as a «representation of what will later occur $(5,6)$. Three lower levels detail the functioning of the operation level (the lowest level is that of tonus) consistent with the description of the central nervous system by Hughlings Jackson (31) and Luria (40) (review in 24, 56). The descriptions by Bernstein $(2,9,10)$ are on the border between activity and neurophysiological description. He links these domains which are usually, but wrongly, considered as separate.

\section{A developmental approach}

One of the main aims of the theory of activity is to apprehend the processes of development in the most general sense. The idea of using development to understand activity was at first very much linked to the principles of dialectical materialism. According to P.P. Blonsky (1921, quoted in ref 67) "Behavior can be understood only as history of behavior". The history of behavior is considered at multiple time scales from phylogenesis to the microgenesis, which are the short term changes observed during learning. This preoccupation is present in Bernstein's works in particular in his synthetic book on dexterity which presents considerations on phylogenesis, child development and learning.

Interaction, mediation, internalisation.

These three notions which are intricately related are essential features of the theory of activity. Interactions, whether social or with the physical environment, are often mediated by tools. Language and symbolic gestures are considered by Vygotski as tools for social interactions (66). 
For example pointing gestures, which are from a developmental point of view unfinished prehension gestures, become expressive means to designate objects and thus are tools for social interactions. This idea led to new interpretations of inner speech in children. Vygostski largely developed these concepts in his studies of the development of disabled children in the framework of defectology (65). Vygotsky considers handicap as a sociocultural developmental phenomenon where compensation comes from socialization and culture (23). He introduced the concepts of 'primary defects' (organic impairment) and 'secondary defects' (distortions of higher psychological functions due to social factors) and in his search for alternative tests for handicapped students, he introduced the notion of the 'zone of proximal development'.

According to the marxist perspective, the followers of the theory of activity underline the dialectic nature of tools since the potential they offer allows the individual to develop himself as well as giving him a means to act on the world. This conception led to the concept of psychological instruments developed by Vygotski: the tools and in general the systems of signs are means for instrumentation. V.V. Ivanov (1977, quoted in ref 67) extends the notion of mediation and considers that behavior cannot be controlled otherwise than through intermediates (tools belonging to systems of signs) "Man cannot govern his own behavior directly and creates signs in order to control it indirectly". The concept of internalization is complementary to those of interaction and mediation. It describes the transition between the external plane of activity, from interaction with the environment to the internal, mental plane. This process supports transformations (generalizations etc.) that will make internalized processes more general, more efficient and able to anticipate future adaptations. This shift from external to internal, which is fundamental for the understanding of learning allows the constitution of a "model of the future" in order to extrapolate in a statistical manner and anticipate «the course of events in the environment» 5,10 review in 11).

The role of social interactions is of minor importance in the work of Bernstein, but the interactions with the environment are critical. Bernstein showed on multiple occasions the importance of interactions with the environment for the organization of movement and for the exploratory strategies used for learning. He rejected the mecanicist interpretation of the control of the biomechanical parameters of locomotion. For Bernstein, motility results from an interaction between the all the structures of the central nervous system with external factors and which evolves over time, the cerebral structures being able to modify themselves as a consequence of experience. What is important is the active search of a motor solution within the variability of the infinite number of possible solutions. Movement coordination according to Bernstein is a much more flexible system than conditioned reflexes and cannot be based on one particular neuronal mechanism but on the organization of the whole common activity.

The idea that we do not command behavior directly is similar to the hierarchical description of control proposed by Bernstein, and to his idea that we do not directly control movement in all its details. The concept of tools, ubiquitous in the theory of activity, is also very significant in Bernstein's work since he dedicated a large part of his experimental work to the use of very varied tools from the hammer to the piano.

\section{The Bernstein-Pavlov controversy}

The early work of Bernstein in the 30's led to the question of the relationship between function and its neuronal substrate (i.e. the question of cerebral localization) and that of plastic changes in the central nervous system. Bernstein blamed Pavlov for considering the conditioned reflex as an isolated pathway (two central points, linked together by a synchronous association link) not generalized and separated from the rest of the personality ${ }^{3}$. This debate meets another debate: that between holism and atomism.

Bernstein was particularly interested in child development and posits that development cannot be reduced to the mechanical result of external influences. By opposition, he claims that learning is also determined by the history of the organism and of its species, and the long lasting traces it has left, in keeping with the concept of activity. For him memory is a huge architecture of facts,

\footnotetext{
${ }^{3}$ This criticism is shared by Luria (see 56).
} 
historically constructed and the support of consciousness as a matter organized in a specific way. In contrast to Pavlov who insisted on the importance of repetition for the rooting of combinations of reflexes, Bernstein claimed in a very modern way, that repetition does not exist since it can never be repetition of the same. The situation is always variable from one occurrence to another; the observer has to consider the whole situation, including the context, the observer himself and the existing memory traces. So repetition induces qualitative and not only quantitative changes (7). For Bernstein, repetition is a primitive way of learning, useful only in the highly simplified and artificial context of the laboratory (the "tower of silence"), in contrast with the rich context of usual, human or animal life. Consistently and in a complementary way, Bernstein claimed that perception is an active search process. Individuals are never passive, according to the concept of activity. "Those aspects of the remaining variability that have no reactive adaptive value can justifiably be looked upon as search-variability, in which the active exploration of the environment, its gradients, the optimal way to act, et cetera, come to the fore" (10 review in 43).

Later, Bernstein suggested that the basis of motor control by the central nervous system is not muscular contractions but synergies which allow the control of the incredible complexity of the human body. He challenged the idea that commands for movements are directly issued by the brain. He posited that performance of any kind of movement results from an infinite variety of possible combinations, or degrees of freedom, of neuromuscular and skeletal elements. The system should, therefore, be considered as self-organizing, with body elements coordinated, or assembled, in response to specific tasks. Bernstein presented an hierarchical organization of the motor system in keeping with the concept of activity, putting in parallel the structure of the CNS according to the neurologist Hughlings Jackson and the phylogenetic description of animal movements. This topology of motor acts also influenced his contemporary, AR Luria (56). The functional hierarchical organization is arranged within levels and between levels (the principle of minimal interaction proposed by (22). Bernstein proposed that motor development was dependent not only on brain maturation, but also on adaptations to body constraints (changes in the growing infant's body mass and proportions) and to exogenous conditions (gravity, surface, specific tasks to be performed). Bernstein coined the term biomechanics, describing the application of mechanical principles and methods to biological systems. Many of the key issues in modern day movement coordination were formulated by Bernstein including the anticipation of the goal, the degrees of freedom problem, motor equivalence, and non-univocality of motor commands and peripheral effects.

\section{Legacy}

Despite the political separation by the Iron Curtain the theories of Pavlov developed largely in the West, particularly through behaviorism formulated and developed by Watson then Skinner. The main works by Skinner in the USA during the 50's 60's coincided with the revival of Pavlovian studies in the USSR. Conversely, the applications of cybernetics were well developed in the USSR. Bernstein formulated in the 30's some key concepts similar to those formulated as cybernetics by Wiener and in the late part of his life, led a seminar devoted to the theoretical implications of cybernetics.

\section{Pavlov and behaviorism}

Expansion of behaviorism in the USA.

Since his Nobel Prize in 1904, Pavlov became universally recognized and celebrated as a major scientist in physiology. His legacy in psychology, based on his later works on conditioning, was developed by American psychologists particularly through the writings of John B. Watson (18781958), who founded behaviorism, and E. Thorndike (1874-1949). This direction differed from Pavlov's general purpose since he noted "that the practical American mind found it more important to know the external behavior of a man, than to guess about his internal state" (42).

Behaviorism became popular in its radical form mainly through the contribution of BH Skinner (1904 -1990) who was an influential American psychologist and founded his own school of experimental research psychology, radical behaviorism, and recognized his dept towards Pavlov (17). The key concept is operant conditioning, sometimes called instrumental conditioning or instrumental learning. Operant conditioning uses the consequences of voluntary behavior or 
response to modify the occurrence and form of behavior. This was demonstrated through systematic experiments in the operant conditioning chamber invented by Skinner. The chamber contained feeding mechanisms, activated by key or lever presses, which enabled measurement of the rate of response. Successful responses producing satisfying consequences (reinforcement) are imprinted and thus will occur more frequently. Unsuccessful responses producing undesirable consequences (punishment) will subsequently occur less frequently. Operant behavior functions within the environment and is maintained by its consequences, while classical conditioning is obtained by modifications of preceding conditions and is not maintained by consequences. Reinforcement, punishment, and extinction, which are the main tools of operant conditioning, are either positive (delivered following a response), or negative (withdrawn following a response). The power of conditioning relies on particular schedules over time with fixed or variable intervals and ratios of reinforcement or punishment as a function of behavioral responses. Extinction is the lack of any consequence following a behavior.

In contrast to classical conditioning in which the unconditioned stimulus (e.g. food) occurs shortly after the conditioning stimulus (e.g. sound) a prior stimulus is not necessary for operant conditioning (although the context of response may be considered as a stimulus). Another difference is that classical conditioning establishes associations between stimuli while operant conditioning establishes associations between response and stimulus.

This behavioral approach has proven to be successful in many areas; in particular it has largely contributed to the development of a psychotherapeutic approach (Cognitive Behavioral Therapy) which aims to influence problematic and dysfunctional emotions, behaviors and cognitions through a goal-oriented, systematic procedure.

Therapy for post-traumatic shock (51) is also based on the work of Pavlov on conditioning to pain and Transmarginal inhibition. This is also the case for methods of extreme mental conditioning procedures or brain washing exerted by several organizations such as military camps.

Hebb and adaptation in formal neural networks.

Pavlov directly influenced the works by D.O. Hebb (1904-1985) a Canadian psychologist who is considered as the father of neuropsychology and neural networks. In particular, he proposed a theory, inspired by classical conditioning at the neuronal level, which became known as Hebbian learning. This method of learning is best expressed by this quote from his book: The Organization of Behavior (30) "When an axon of cell $A$ is near enough to excite cell $B$ and repeatedly or persistently takes part in firing it, some growth process or metabolic change takes place in one or both cells such that A's efficiency, as one of the cells firing B, is increased" This is often paraphrased as "Neurons that fire together wire together." The mechanism of Hebbian learning was a source of the development of learning in artificial neural networks. Creation of some modern artificial neural networks is still based on the transmission of signals via electrical impulses and Hebbian synapses.

Hebbian learning and cerebellar physiology

The Hebbian theory also had great impact in neuroscience in the field of cerebellar physiology (29). The convergence of parallel fibers and climbing fibers on Purkinje cells was initially proposed as being a Hebbian synapse. Later, Ito confirmed experimentally the phenomenon of long term depression (LTD) i.e. the decrease in transmission between parallel fibers and Purkinje cells after conjunctive stimulation of the parallel fibers and climbing fibers. It is now largely admitted that the microcomplex of the cerebellar networks and LTD could be the basis of an adaptive mechanism in the brain and the acquisition of adaptive models ${ }^{4}$ (see below).

Bernstein and Russian cybernetics

$4 \quad$ "Initially all parallel-fiber synapses on Purkinje cells may be functional, so that Purkinje cell are fully activated by a mossy fiber input and in turn inhibit nuclear neurons that otherwise might be activated by the mossy fiber input. If the consequent silence of nuclear neurons results in errors, climbing-fiber signals are generated to depress the parallel-fiber-Purkinje cell transmission, thereby releasing nuclear neurons from Purkinje cells inhibition and generating output from the microcomplex. This will lead to improvement of the overall system performance with 8 reduced errors." (29). 
Conversely to behaviorism, Cybernetics was born in the USA but was developed particularly in the USSR, both on the applied and fundamental sides. Bernstein is also considered as a pioneer in the theoretical branch of Eastern Cybernetics.

Cybernetics, the science of the control of regulated systems, is based on a modeling of exchanges and information and principles of interaction. It relates more to the functioning of the whole system than the analysis of the components. It was later designed as the science of mastered analogies between organisms and machines.

Cybernetics began in the USA as an interdisciplinary science in the 1940's during the Macy conferences for which mathematicians, logicians, anthropologists, psychologists and economists who aimed to build a general science on mind functioning all gathered. This was formalized by the mathematician Norbert Wiener (1894-1964) in his book "Cybernetics, or Control and Communication in the Animal and the Machine", which was published in 1948 (68). The "first cybernetics" was later divided into three branches: cognitive sciences, artificial intelligence and a movement known as second-order cybernetics (review in 18). Second-order cybernetics is a theory of auto-organizing systems formalized in the 50's by the Heinz von Foerster (1911-2002) an Austrian-American physician and philosopher. In the field of biology, this trend initiated by Maturana and Varela, $(41,64)$ and Atlan (1) was particularly fertile in France.

Wiener's book was published in the USSR in 1958 and became very popular. At the end of the 1950s and the beginning of the 1960s, there was a cybernetics boom in the USSR. In contrast to the few academic cybernetics departments in the USA, many cybernetics departments were created in universities and scientific institutions of the USSR. Most of these organizations had a practical technical purpose for engineering.

Bernstein did not participate in the founding of cybernetics in the 40's. However, he is recognized for his contribution to the description of neuromuscular feedback a key concept of cybernetics, and for proposing its strict mathematical definition in differential equations (62). Bernstein's idea largely influenced the thinking in the USSR with regard to the biological basis of cybernetics. After their meeting with Bernstein, the famous mathematician I.M. Gelfand (1913- ) and the theorist physicist M.L. Tsetlin created a laboratory in the institute of information transmission where they initiated a multidisciplinary seminar with the biologist V.S. Gurfinkel. Their contribution was mainly related to the stream of second-order cybernetics. Bernstein and his colleagues in the multidisciplinary seminar, contributed largely to the influence of fundamental research on control in the USSR and this was largely disseminated in the world from the end of the 60 's. People participating in this seminar became the relay for Bernstein's thinking particularly on movement sciences.

The works of Bernstein were little known in the West until the translation and publication in 1967 of a book written in 1935 (5) "The coordination and regulation of movement". After that, his influence grew as demonstrated by the exponential curve of quotations. He was recognized as a pioneer and quoted even by scientists who defended ideas far from his own. His direct disciples (Berkenblit, IM Feigenberg, AG Feldman, LP Latash, ML Latash, GN Orlovsky, GL Shik... ), many of whom emigrated to the West after 1990, developed his scientific legacy. A scientific society exists with the aim of developing Bernstein's legacy ${ }^{5}$ and regular international meetings are organized. In France, collaboration between French and Russian scientists renewed the tradition elicited by E.J. Marey on the physiology of sensorimotor activity.

\section{Presence and impact on motor control and sensorimotor learning today}

Pavlov and Bernstein had very different personal destinies. During the 30's Pavlov was a universally respected Nobel Prize winner and Bernstein a younger physician and scientist working in a difficult historical context. Both were great scientists whose legacy extends well beyond their own work. Their dialog is materialized by a book "Contemporary issues on the physiology of the central nervous system (7)" which testifies the theoretical, experimental and historical richness of their controversy in particular on the mechanism of learning. Now, more than 70 years later, after

International Society for motor control. http://www.i-s-m-c.org 
complicated streams of scientific influence in new disciplines such as behaviorism and cybernetics, as well as complicated exchanges between Eastern and Western scientific traditions, an echo of their controversy remains. Despite an exponential growth of knowledge on learning, brain function and sensori-motor control, the controversy between two "types" of theories corresponding to two "types" of learning mechanisms remains vivid. On the one hand, we largely recognize the wide legacy of Pavlov in the mainstream view on motor control and learning. On the other hand, several scattered theoretical alternatives (dynamical systems approach, ecological psychology, motor control) defend minority ideas close to those defended by Bernstein and his direct followers.

\section{Motor control: problems to solve in the control of movement.}

This opposition in ideas can be illustrated on the question of motor control, i.e. on the mechanisms by which the central nervous system commands and controls the complex mechanical structure of the body. Bernstein is especially famous for evidencing the theoretical questions related to motor control (6). Indeed, the apparent ease with which we move and smoothly execute simple goal directed gestures contrasts deeply with the complexity of the problem. The first aspect is that of multilevel redundancy. In general, the human body has at his disposal a larger number of degrees of freedom (DoF) that is necessary for the task. This is true at the anatomical level of the joints: for example to reach an object in 3D space, $6 \mathrm{DoF}$ are needed (to position and orientate the hand relative to the object) however, the human arm has at least 7 DoF (3 rotations in the gleno-humeral shoulder joint, 2 in the elbow, 2 in the wrist, without mentioning the trunk, scapula and hand). This redundancy is still greater if we consider muscles (in general several muscles can activate one rotation, many muscles are bi-articular etc... ), or even motor units. So redundancy affords multiple ways to execute a movement. The second aspect is linked to Newtonian laws of mechanics that work on our body. All movements are performed within the field of gravity. In addition, the body is structured as a multi-link effector, so any movement of one segment has consequences on the neighboring segments, due to action-reaction effects, and finally on the whole body chain until the postural support, so that the dynamical interactions of rotating segments are mathematically very complex. These interactions are prone to induce an important perturbation of the movement. Therefore any movement, not only involves the control of the joints that had to be moved but also the stability of the other joints and generally the simultaneous control of posture and equilibrium. This postural control is anticipatory since it is generated before the onset of movement (12).

Actions are generally goal directed so that moving involves a representation of the future as underlined by Bernstein according to the theory of activity. Goal directed action opens the question of anticipation for motor control (32).

In addition, the environment within which the movement is performed may itself induce external perturbations; some can be anticipated and predicted (i.e. obstacles or interactions with objects) other may cause unexpected perturbations or cannot be exactly predicted due to some variability and noise.

So, human or, more generally, biological motion implies the mastering of a complicated mechanical mobile in the field of gravity. However movements are characterized by a smooth execution, and by a great regularity evidenced by well-known kinematic invariants. For example, the movement of the finger for a goal directed task like pointing has a linear trajectory and a smooth velocity profile, both showing that the constraints of motor control are anticipated by the central nervous system before the onset of movement (32). The mechanism of anticipated control is disputed, but all the theories concur to the idea that those mechanisms have to be acquired during the development and continuously updated during life, by a continuous adaptation process.

Acquisition of internal models and programs: role of reinforcement learning.

The concept of motor programs means that the details of the movement are generated by an anticipatory mechanism, before the onset of movement itself. Theoretical work on motor programs stem from both a psychological and a neurophysiological context.

Schmidt and generalized motor programs

The most classical view on motor anticipation is the idea of motor program, or schemata as 
proposed by Schmidt (52). For him, the motor programs were generalized for a same action and each movement instance was influenced by parameter as a function of sensory information. The idea of generalized programs avoided the need for extensive memory storage. For him, the schema was "a rule developed by practice and experience across a lifetime, which described a relationship between the outcomes achieved on past attempts at running a program and the parameters chosen on those attempts" (52). Schmidt distinguished recall schemata (relationships between the parameters of the program and the outcome, and recognition schemata (relationship between the past sensory consequences generated by the program and the outcome of the program) and he described the role of feedback for the permanent tuning and adaptation of the parameters of these schemata constituting the generalized motor program. He also formalized the distinction between several kinds of feedback information (Knowledge of Results or KR and Knowledge of Performance or KP, see Robertson et al. this volume) that both act as reinforcement. The theory of generalized motor programs is not behaviorist but keeps the emphasis on repetition in order to evoke the "correct movement" and the idea that that the perceptual trace in memory is an increasing function of the number of repetitions ("law of exercise", initially proposed by Thorndike (60). Recent experiments with augmented feedback did not always obey the predictions of the theory (review in 55). Perhaps because the generalized motor program theory explains the improvement of motor execution, but not the acquisition of the program, when evidence suggests that KR may act more on the acquisition of the skill itself than on the tuning of the parameters. This theory does not explain for example motor learning by mental practice and it is suggested that all the repetitions of the task are not equivalent and that cognitive effort could weigh the effect of each repetition (55).

\section{Brain control of movement}

A great number of studies in neuroscience have investigated the neuronal mechanisms of motor control and learning. Classically, motor control is assumed to be hierarchical with relatively sequential but overlapping steps: planning as a function of task requirement in the prefrontal cortex (34); coordination as a function of initial condition and context in a network between premotor and parietal associative areas (15); then execution in the primary motor area with activation of the pyramidal neurons.

In this context, the acquisition of motor behavior is related to the adaptation and plasticity of brain structures the cerebral and cerebellar cortices and basal ganglia.

\section{Adaptive motor learning and internal models in the cerebellum}

Many studies devoted to the control of smooth movement and its adaptation to changing conditions of execution focused on the cerebellum following the description by Ito of the properties of the cerebellar microcomplex (see above). Indeed, the structure of the cerebellum could be the neuronal basis of internal models. Models of adaptive learning based on cerebellar wiring diagrams have been used to understand how the central nervous systems adapts itself to control the complex mechanics of the body. The cerebellum can form "an internal model mimicking the motor plant that is controlled by the motor cortex" (29) ${ }^{6}$. Such a forward internal models predicts the consequences of actions and can be used to overcome time delays associated with feedback control. Later, Kawato proposed that the cerebellum also used inverse models that can provide the neural command necessary to achieve some desired trajectory (33). A more recent model of cerebellar function includes multiple paired forward and inverse models. This arrangement could explain both motor learning and control (70). The progressive learning within the cerebellar forward and inverse models is tuned to progressively reduce errors in order to obtain one optimal solution minimizing the cost of the movements and the noise in the command (review in 61). Optimization, as a result of

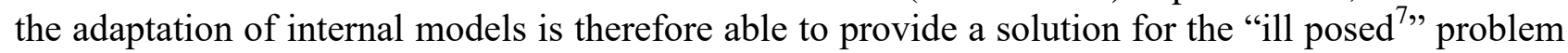
of redundancy (26). Learning in such a circuit is supervised, since the objective is given by the task and the mechanisms operate to converge on a reduction of the errors given by the feedback.

6 Forward and inverse model are terms stemming from engineering and robotics that can be put together with recall and recognition schemata respectively. 7 The coordination of a redundant system is an "ill posed" problem since it has no unique solution. 
The cerebellum is now viewed as the stocking structure of multiple models of the environment or tools mediating the movements. The choice of a particular model would be occur as a result of the dense reciprocal relationships between the cerebral associative areas and the cerebellum. These models are backed up by experimental evidence with motor learning and adaptation paradigms and brain imaging studies $(27,28)$. In a recent review, based on studies in patients with lesions of the central nervous system, Shadmehr and Krakauer (54) map the functional aspect of such an integrated model of motor control between the cerebellum, cortical brain areas and the basal ganglia.

Theories based on motor programs do not exclude corrective on-line control of movement that is now largely demonstrated (48).

Although these theories are far from behaviorism since their aim is to "open the black box" and investigate the neuronal basis of motor control, they still rely heavily on Pavlov's view on leaning. First, the historical lineage relayed by Hebb is clear; second the experimental paradigms share a surprising common basis which is the role of feedback for supervision and reinforcement, the great number of movement trials, the goal of optimization, the objective to reduce the variability, the emphasis on repetition and the mechanism by the formation of a neuronal trace whose strength increases with repetition. The kinematic invariants are in general viewed as optimal solutions that are what needs to be specifically learnt.

\section{A dynamical view on motor control in Bernstein's tradition.}

Besides these main stream theories on motor control, based on the idea of motor programs and internal models, several concurrent theoretical approaches have been developed. These approaches are quite diverse but share common principles based on systemic models rooted in the action perception cycle with a common reference to Bernstein.

Synergies and the use of variability

Learning is the result of activity and of spontaneous exploration of the possible actions depending on the context. The focus is put on variability of the different instances of movements instead of repetition of the same, on the importance of varied and rich sensory information in a natural context, on sudden success and on the long lasting remaining skill. For example, in order to learn to ride a bike, a child has to make many attempts but the exact conditions, the sensory-motor context including the help of adults vary from one attempt to another and are far from being repetitions of the same movement. Then, the child finally succeeds in the mastering of the very complex dynamical interactions between his movements, the forward progression of the bike and the complex dynamical equilibrium of the cyclist and bike pair. This sudden understanding is what Bernstein called with humor in "Dexterity" the "aha" effect. Once somebody has learned to ride a bike, he can improve velocity or other parameters but the skill itself is never forgotten, in contrast to the gradual extinction of Pavlovian conditioned reflexes.

As Bernstein showed the full mastering of professional, artistic or sports skills (hammering, playing piano...), needs many repetitions of intensive practice in variable conditions of execution. Joint coordination is always different, despite the kinematic regularity of the part of the limb which is most important for the task; the working point (36). Bernstein's followers, along with Gelfand, demonstrated how variability is positive, since it allows accommodation of the trial to trial variations of the context. Gelfand and Latash (21) proposed the replacement of the word redundancy by the word abundance ${ }^{8}$. In this framework, the redundancy of the motor system is not an "ill posed problem" but a fundamental characteristic of motor control, allowing fluidity, flexibility and adaptability of motor acts as well as their automatic resistance to perturbation. Movement in the different degrees of freedom is organized is such a way as to maintain the important variables for the task, while releasing the variability in the other degrees of freedom (53, 63, review in 38). According to this hypothesis, synergies are organized according to two

8 The russian word for redundancy may have both meanings. 
complementary properties: i) co-variation in several DoF which can to combine additively in order to reduce the dimensionality of the control, ii) automatic compensation from one DoF to another, in case of perturbation or random fluctuation of execution. This latter property corresponds to motor equivalence (25).

\section{Mass-spring models and equilibrium point control}

Complementary to Bernstein's work, AG Feldman has been developing since the 60's, the theory of equilibrium point control in which the limbs are modeled as a mass-spring mobile (review in ref 19). This theory can be generalized to a redundant system: in this case the command specifies a referent configuration corresponding to a set of thresholds for the recruitment of motoneurons. The final configuration of the limb reaches its final state according to the central command (referent configuration) and to the mechanical constraints in the environment (i.e. the command moves the limb if it is free or increases the force in an isometric situation). Thus, the force is not directly specified by the central nervous system but results from the dynamical interactions between the command and the biomechanics of the limb and of the environment, including gravity (44). Therefore, the equilibrium point theory avoids the need for an internal model of the limbs and environment, since the necessary adaptation to changing conditions occurs through tuning of the command from trial to trial (20).

Dynamical systems for learning and development

Another influential stream of research is based on the concept of dynamical systems. The common basis of this thinking is inspired by the physical models of non linear dynamical systems, an area of applied mathematics used to describe the behavior of complex interactions usually by employing differential equations. Models of coupled oscillators have been applied with success on rhythmic movements which have been largely studied by this school, for example juggling (3) in line with Bernstein's early study on the dynamics of piano playing (5). These theories oppose the theories of motor programs and internal models. Here the focus is put on the interactions between the subject and his environment and the auto-organization of the behavior rather than on supervised learning. The priority in this line of thinking, is not to investigate the neuronal basis but to understand the construction of behavior and cognition resulting from the action perception cycle in a constructionist way. This view is in agreement with that of Gibson, the founder of ecological psychology, who argued that animals and humans form a "system" with the environment, such that, to fully explain some behavior it is necessary to study the environment in which this behavior took place. The environment affords opportunities for actions, the "affordances" which critically depend on the individual body of the person (or animal!) acting. The arrangement of the environmental context of action as a field of promoted actions is a mean for adults or experts to encourage the discovery and learning of new skills in the developmental or academic context $(14,49)$. The concepts of affordance and the "field of promoted actions" allow the bridging of the gap between recent advances in psychophysiology of action and perception and the sociocultural theories for the dynamical construction of behavior during development and learning, initiated by Vygotski in the 30's (66).

In most cases, dynamical models of interactions are not explicitly modeled but rather used as a metaphor. Dynamical systems theory deals with long-term qualitative behavior and uses the concepts of physics: self organization (the spontaneous creation of coherent forms), emergent properties, limit cycle... Experimentally, the focus is put on i) long term observation of a small number of individuals, taking into account their own bodily characteristics (e.g. respiratory, circulatory, nervous, musculo-skeletal, perceptual) ii) the characteristics of the environment (perceptual, mechanical...) iii) the aim being to investigate the determinants of the transitions between behaviors. An influential theorist in this field is E.Thelen $(58,59)$ who studied the motor development of children. She showed that the onset of behavior depended on many intricate factors involving not only the maturation of the central nervous system but also the characteristics of the body, or its state, and of the environment. For example, she showed that infant stepping which is present after birth can be elicited before the acquisition of locomotion in a pool, suggesting that it is masked by biomechanical factors, and can be released when the constraints of gravity are lessened 
by water. Similar analysis aims to understand the particular construction of behavior of individuals whatever their condition. Latash and Anson (37) proposed that the movement patterns observed in pathological conditions should not be considered as pathological but "atypical" since they may represent the best motor solution for a person taking into account his/her impairment and life context. However, this position is contested; "atypical" movements may have detrimental consequences or may limit rehabilitation and finally lead to a poorer outcome.

In opposition to the reductionist approach of mental activity on neuroscience, these approaches share the ambition to develop non reductionist materialistic theories of human activity (10).

\section{Conclusion}

In summary, the impressive legacy of Pavlov has fertilized very different fields in psychology, neuroscience and formal neurons. It is commonly accepted in the community and very largely applied for leaning, teaching, and therapy with unquestionable efficiency. It remains nowadays the main stream paradigm for learning and adaptation and has received much evidence from basic and integrated neuroscience.

Although quite varied, the approaches in Bernstein's tradition share common principles that differ markedly from the tradition of conditioning inherited from Pavlov. The drive for learning is action itself and not stimuli. The focus is put on dynamical processes and not on representation (called traces by Pavlov) and on the sensori-motor history of each individual. All the elements of interaction are considered, including the characteristics of the body structure and the multiple facets of the physical, social and cultural environment. The theories of reference are more related to physical models of auto-organization and autopoiesis than to neuronal models developed by computational neuroscience. In addition, the concept of activity allows dualist positions to be rejected as Leontiev suggests: "We must analyze the system of objective activity in general. This includes the corporal subject - the brain and the perceptual and motor organs" (39).

However, rather than being alternative, these two streams of research should be presented as complementary approaches since they do not really share the same object of research. Skinner claimed "neuroscientists need science of behavior; without it, they would not know what to look for in the nervous system and therefore might look for things they would never find" (quoted in 17). An analysis of activity in the physical and socio-cultural context (and not only of behavior) should precede and complement research on brain activity. For both scientific and sociological reasons, a synthesis is still to come. The hazards of life and history in a particularly troubled period meant that the physiology of activity proposed by Bernstein as a new paradigm (35) remained of minority interest and did not evoke a generally accepted shift in scientific thinking.

However, the authors hope that the readers of the present text will share their fascination for the destiny of these two eminent people, both as men and as researchers, who so brilliantly personify the ongoing hot debate on learning.

\section{Acknowledgments}

The authors are indebted to Nicolas Balzamo for the translation in French of a chapter of Bernstein (1936/2003). The translation was supported by the Federative Institute for Research on Disability (IFR 25). We thank Johanna Robertson for reviewing the English. A. Roby-Brami is supported by INSERM. Original pictures of I.P. Pavlov and N.A. Bernstein by Emile Brami, copyright Emile Brami. 


\section{References}

1. Atlan H, 1979, Entre le cristal et la fumée, Seuil, Paris.

2. Bassin PV, Bernstein NA, Latash LP (1966) (English translation 1999): On the problem of the relation between structure and function in the brain from a contemporary viewpoint. In: Latash LP, Latash ML, Meijer OG, Part I. Motor Control (1999) 3: 329-332, 342-345. Part II. Motor Control. (2000) 4:125-149.

3. Beek PJ, Turvey MT (1992) Temporal patterning in cascade juggling. J Exp Psychol Hum Percept Perform. 18:934-947.

4. Bernstein NA, Popova (1930) Studies on the biodynamics of the piano strike (English translation 2003) In : Kay BA, Turvey MT, Meijer OM (2003) An early oscillator model, Studies on the biodynamics of the piano strike. Motor control, 7: 1-45..

5. Bernstein NA (1935) (English translation 1967) The coordination and regulation of movements. Pergamon press, Oxford.

6. Bernstein NA (1945) (English translation 1998) The current problem of modern Neurophysiology. In: Sporns O and Edelman G.M. Bernstein dynamic view of the brain: the current problem of modern neurophysiology. Motor Control 1998, 2, 283-305.

7. Bernstein NA, (1936-2003) Contemporary issues on the physiology of the central nervous system. (in Russian) Smysl, Moscou.

8. Bernstein (1947), The construction of movement (in Russian). Moscow.

9. Bernstein NA (1947-1991) (English translation 1996) Dexterity and its development. In Latash ML and Turvey MT Dexterity and its development, (1996) Lawrence Erlbaum, New Jersey. 1-235.

10. Bernstein NA, (1965) (English translation 2000) On the road towards a biology of activity. In: Bongaardt R, Pickenhain L, Meijer OG. Bernstein's anti-reductionistic materialism: On the road towards a biology of activity Motor Control. (2000) 4: 377-406.

11. Bongaardt R, Meijer OG (2000). Bernstein's theory of movement behavior: historical development and contemporary relevance. Journal of Motor Behavior, 32: 57-71.

12. Bouisset S, Do MC (2008) Posture, dynamic stability, and voluntary movement. Neurophysiol Clin, 38: 345-362.

13. Brazier M. (1977) la neurobiologie du vitalisme au matérialisme. La recherche, 83: 965-972.

14. Bril B (2002) Apprentissage et contexte, Intellectica, 35 : 251-268.

15. Burnod Y, Baraduc P, Battaglia-Mayer A, Guigon E, Koechlin E, Ferraina S, Lacquaniti F, Caminiti R (1999) Parieto-frontal coding of reaching: an integrated framework. Exp Brain Res 129:325-346.

16. Buser P (2006) Slowly forgetting the Pavlovian adventure? C R Biol. 329: 398-405.

17. Catania C, Laties VG (1999) Pavlov and Skinner: two lives in science (an introduction to BF Skinner's "Some responses to the stimulus 'Pavlov"”, J. Exp Anal. Behav. 72: 455-461

18. Dupuy JP (1994) Aux origines des sciences cognitives, La Découverte. Paris.

19. Feldman AG, Goussev V, Sangole A, Levin MF (2007) Threshold position control and the principle of minimal interaction in motor actions. Prog Brain Res.165: 267-281.

20. Foisy M, Feldman AG (2006) Threshold control of arm posture and movement adaptation to load. Exp Brain Res 175: 726-744.

21. Gelfand I, Latash ML (1998) On the problem of adequate language in motor control. Motor Control, 2, 306-313.

22. Gelfand IM, Tsetlin ML (1966). On mathematical modelling of the mechanisms of the central nervous system. In: Gelfand IM, Gurfinkel VS, Fomin SV, Tsetlin ML, eds, Models of the structural-functional organisation of certain biological systems, Nauka, Moscow, pp. 9-26 (english translation: 1971 MIT press, Cambridge).

23. Gindis B (1995) Viewing the Disabled Child in the Sociocultural Milieu. Vygotsky's Quest. School Psychol; Int. 16: 155-166

24. Glozman, J. M. (2007) A.R. Luria and the History of Russian Neuropsychology, Journal of 
the History of the Neurosciences, 16:1, $168-180$.

25. Gracco GL, Abbs JH (1986) Variant and invariant characteristics of speech movements. Experimental Brain Research, 65: 156-166.

26. Guigon E, Baraduc P, Desmurget M. (2007) Computational motor control: redundancy and invariance. J Neurophysiol. 97: 331-347.

27. ImamizuH, Kuroda T et al. (2003). Modular organization of internal models of tools in the human cerebellum. Proc Natl Acad Sci U S A 100(9): 5461-6.

28. Imamizu H, Kuroda T, Miyauchi S, Yoshioka T, Kawato M (2003) Modular organization of internal models of tools in the human cerebellum. Proc Natl Acad Sci U S A 100: 5461-5466

29. Ito M (2002) Historical review of the significance of the cerebellum and the role of Purkinje cells in motor learning. Ann. N.Y. Acad Sci. 978: 273-288.

30. Hebb DO (1949) The Organization of Behavior : A Neuropsychological Theory, Wiley, New York.

31. Hughlings Jackson $\mathbf{J}$ (1889) On the comparative study of disease of the nervous system. British Medical Journal, 355-362.

32. Jeannerod M (1988) The neural and behavioral organization of goal-directed movements. Oxford, Clarendon Press.

33. Kawato M, Furukawa K, Suzuki R (1987) A hierarchical neural-network model for control and learning of voluntary movement. Bio. Cybern. 57: 169-185.

34. Koechlin E, Ody C, Kouneiher F (2003) The architecture of cognitive control in the human prefrontal cortex. Science 302: 1181-1185.

35. Kuhn TS (1962), The Structure of Scientific Revolutions. University of Chicago Press, Chicago.

36. Latash, M.L. (1996) The Bernstein problem: how does the Central Nervous System make its choices ? In: Dexterity and its development. Eds: Latash ML and Turvey MT, Lawrence Erlbaum, New Jersey, 277-303.

37. Latash M.L., Anson G. (1996) What are "normal movements" in atypical populations. Behav. Brain Sci. 19: 55-106.

38. Latash ML, Scholz JP, Schöner G (2007) Toward a new theory of motor synergies. Motor Control, 11:276-308.

39. Leontiev AN, (1972) (English translation 1981) The problem of activity in psychology. In: The concept of activity in soviet psychology. Wertsch, J. (ed.). (1981). Armonk, New York: M.E. Sharpe, Inc. p 37-71.

40. Luria AR (1969) (French translation 1978) Les fonctions corticales supérieures de l'homme, (1978) PUF, Paris.

41. Maturana H. and Varela F, (1980) Autopoiesis and Cognition: The Realization of the Living. Boston Studies in the Philosophy of Science. Eds Cohen, Robert S., and Marx W. Wartofsky, Vol. 42, Reidel Publishing, Dordecht.

42. Medvedeva TA (2008) Cybernetics and the Russian Intellectual Tradition. Conference Cybernetic Heritage in the Social and Human Sciences and Beyond, Centre for Baltic and East European Studies (CBEES) Södertörn University, Stockholm.

43. Meijer OG,. Bruijn SM (2007) The Loyal Dissident: N.A. Bernstein and the Double-Edged Sword of Stalinism', Journal of the History of the Neurosciences, 16: $206-224$.

44. Ostry DJ, Feldman AG. (2003) A critical evaluation of the force control hypothesis in motor control. Exp Brain Res. 153: 275-288.

45. Pavlov IP (1903) The experimental psychology and psychopathology of animals. 14th International Medical Congress in Madrid.

46. Pavlov IP (1927) Conditioned reflexes: an investigation of the physiological activity of the cerebral cortex. http://psychclassics.yorku.ca/Pavlov/index.htm

47. Pavlov IP, (1904) Autobiography / Biography In: Nobel Lectures, Physiology or Medicine 1901-1921, (1967), Elsevier Publishing Company, Amsterdam. http://nobelprize.org/nobel_prizes/medicine/laureates/1904/pavlov-bio.html. 
48. Prablanc C, Desmurget M, Gréa H (2003) Neural control of on-line guidance of hand reaching movements. Prog Brain Res. 142: 155-170.

49. Reed E, Bril B (1996) The primacy of action in development. A commentary of N. Bernstein. In: Dexterity and its development. Eds: Latash ML and Turvey MT, Lawrence Erlbaum, New Jersey, 431-451

50. Samoilov VO (2007) Ivan Petrovich Pavlov (1849-1936). Journal of the History of the Neurosciences, 16, $74-89$.

51. Sargeant W (1957) Battle for the Mind: A Physiology of Conversion and Brain-Washing. Malor Books.

52. Schmidt, R. A. (2003). Motor schema theory after 27 years: reflections and implications for a new theory. Res Q Exerc Sport 74(4): 366-75. Review.

53. Scholz JP, Schöner G, Latash ML (2000) Identifying the control structure of multijoint coordination during pistol shooting. Exp Brain Res, 135: 382-404.

54. Shadmehr R, Krakauer JW. (2008) A computational neuroanatomy for motor control. Exp Brain Res. 185: 359-381. Schmidt, R. A. (1975). A schema theory of discrete motor skill learning. Psychological review 82: 225-260.

55. Sherwood DE, Lee TD (2003) Schema theory: critical review and implications for the role of cognition in a new theory of motor learning. Res Q Exerc Sport 74: 376-82.

56. Siksou M, (2008) Les psychologues de la Troïka et la notion de fonction. In F. Parot Fonctions en psychologie. Wavre. Mardaga.p. 161-185.

57. Smith GP (2000) Pavlov and integrative physiology, Am J Physiol Regulatory Integrative Comp Physiol 279: 743-755

58. Thelen E, Corbetta D, Kamm K, Spencer JP, Schneider K, Zernicke RF (1993) The transition to reaching: mapping intention and intrinsic dynamics. Child Dev. 64: 1058-1098.

59. Thelen E., Smith L.B. (1994) A dynamic systems approach to the development of cognition and action. Cambridge, A Bradford book, MIT press.

60. Thorndike E (1932). The Fundamentals of Learning. New York: Teachers College Press.

61. Todorov E (2004) Optimality principles in sensorimotor control. Nat Neurosci. 2004 7: $907-$ 915

62. Trogemann G, Nitussov AY, Ernst W (2001) Computing in Russia: The History of Computer Devices and Information Technology Revealed. VIEVEG (Bertelsmann, Springer), Wiesbaden.

63. Tseng Y, Scholz JP, Schöner G, Hotchkiss L (2003), Effect of accuracy constraint on joint coordination during pointing movements. Exp. Brain Res. 149, 276-288.

64. Varela F, Thompson E, Rosch E, (1991) The Embodied Mind: Cognitive Science and Human Experience. MIT Press, Cambridge MA.

65. Vygotski LS, (1928) (French translation 1994) Textes choisis In : Vygotski : Défectologie et déficience mentale. Barisnikov K, Petitpierre G, (eds), Delachaux et Niestlé, Neuchâtel, $258 \mathrm{p}$.

66. Vygotski LS, (1934) (French translation 1997). Pensée et Langage, 1997, La Dispute, Paris.

67. Wertsch JV (1979) The concept of activity in soviet psychology. An Introduction. In: The concept of activity in soviet psychology. Ed Wertsch J, Sharpe, New York.

68. Wiener N (1948) Cybernetics: Or the Control and Communication in the Animal and the Machine. Paris, France: Librairie Hermann \& Cie, and Cambridge, MA: MIT Press.Cambridge.

69. Windholz G (1992) Pavlov's conceptualization of learning Am J Psychol. Fall;105(3):45969.

70. Wolpert DM, Miall RC, Kawato M (1998) Internal models in the cerebellum. Trends in Cognitive Sciences 2: 338-347. 